\title{
Technological value of blends (bread wheat flour and durum wheat semolina) for bread manufacture
}

\author{
Ana Sofia Bagulho ${ }^{1,3 *}$, André Monho', Ana Sofia Almeida ${ }^{1}$, Rita Costa $^{1}$, José Moreira ${ }^{1}$, Isabel Pais ${ }^{2,3}$, \\ Paula Scotti ${ }^{2,3}$, José Coutinho', Benvindo Maçãs ${ }^{1}$ \\ ${ }^{1}$ National Institute for Agrarian and Veterinarian Research, Estrada Gil Vaz, Ap. 6, 7350-901, Elvas, Portugal, ${ }^{2}$ National Institute for Agrarian \\ and Veterinarian Research, Quinta do Marquês, Av. República, 2784-505 Oeiras, Portugal, ${ }^{3}$ GeoBioTec, Faculdade de Ciências e Tecnologia, \\ Universidade Nova de Lisboa (FCT/UNL), 2829-516 Caparica, Portugal
}

\section{A B S T R A C T}

\begin{abstract}
In the present study, the rheological and baking properties of blends containing bread wheat flour and durum wheat semolina were analyzed. Two bread wheat varieties (Almansor, Pirana), three durum wheat varieties (Celta, Hélvio, Marialva) and two replacement levels (25 and $60 \%)$ were used to determine differences in dough behaviour and bread properties. These varieties showed difference in their properties, once they have different allelic composition for the most determinant loci to quality (G/u-1 in bread wheat and G/u-3 in durum wheat). The addition of durum wheat semolina to Almansor flour had a deleterious effect on the main all quality parameters. The dough stability and loaf volume of Pirana flour (weak bread wheat) could be improved when blends were made with Hélvio's semolina. The replacement level of durum wheat in both types of blends increased alveograph $\mathrm{P} / \mathrm{L}$ and yellowish crumb colour but decreased alveograph deformation energy $\mathrm{W}$ and loaf volume of blends with Almansor. This study showed the possibility of making bread with acceptable characteristics using mixtures of bread and durum wheats, although, can cause lower bread volume.
\end{abstract}

Keywords: Bread wheat; Durum wheat; Breadmaking quality

\section{INTRODUCTION}

Durum wheat has been used, primarily, to produce pasta products but, also, has the potential for breadmaking (Boyacioglu and D'Appolonia, 1994c; Hareland et al., 1998). In some areas of the world, this crop is used to produce different types of flat and leavened bread (Liu et al., 1996), usually with a smaller loaf volume than those from bread wheat, but, with a yellowish colour, a characteristic taste and structure, a longer shelf-life and slower staling, which appeals to customers (Boyacioglu and D’Appolonia, 1994b; Liu et al., 1996). Blending this flour/ semolina with bread wheat flour can be used to minimize this problem. However, blends can cause uneven hydration which affects the bread due to differences in water absorption and rate of hydration of the two flours (Sissons et al., 2008). The addition of durum wheat flours has been found to be useful to improve breadmaking properties of poor quality common wheat and for extending the shelf life of the derived products (Boggini and Pogna, 1990; Torbica et al., 2011; Licciardello et al., 2013).
Good breadmaking flour requires strong gluten to form an extensive and viscoelastic matrix during dough formation, still maintaining good handling properties (Liu et al., 1996). Durum wheat, usually, has higher protein content, but shows inferior rheological properties when compared to bread wheat dough, because its gluten is very weak, viscous and inelastic (Boyacioglu and D'Appolonia 1994a; Liu et al., 1996).

The importance of gluten and its components on breadmaking quality has been strongly debated in the literature. It is widely accepted that gliadins confer viscous properties to gluten and are required for dough development, while glutenins (HMW-GS - high molecular weight glutenin subunits and LMW-GS - low molecular weight glutenin subunits) impart strength and elasticity, which are essentials to hold gases produced during fermentation process (Dhaka et al., 2015). HMW-GS represents about $12 \%$ of the total grain protein, but it has been shown that the composition of the HMW-GS alone,

\footnotetext{
${ }^{*}$ Corresponding author:

Ana Sofia Bagulho, INIAV - National Institute for Agrarian and Veterinarian Research, Estrada Gil Vaz, Ap. 6, 7350-901 Elvas, Portugal. Phone: 003512948573, Mobile: 351 965146855, E-mail: ana.bagulho@iniav.ptt
} 
may account for up to $60 \%$ of the total variation in the quality of bread flour and the presence of $5+10$ subunits coded by Glu-D1 locus is fundamental to breadmaking quality (Payne et al., 1987). Genetically, durum wheat are tetraploids $(\mathrm{AABB})$ without the $\mathrm{D}$ genome that is present in hexaploids (bread wheat - AABBDD). The removal of the $\mathrm{D}$ genome from bread wheat greatly reduces its baking potential and it is considered, at least, partly responsible for the relatively poor baking quality of durum wheat (Sapirstein et al., 2007).

Breeding programs are promoting the increase of protein content and quality characteristics, both, on bread and durum wheat, in order to obtain better flour and semolina parameters to satisfy the needs of the industry and the consumers.

The reason for this study comes from the need to promote the diversification, on what concern to the main use of durum wheat, by using its semolina in different mixtures with flour of bread wheat for baking purposes. The use of durum wheat for bread making industry becomes very interesting, nowadays, as a return to its traditional utilization since many years ago, when consumers used the raw material indistinctly (bread and durum wheat) for baking.

\section{MATERIALS AND METHODS}

\section{Wheat germplasm}

This study was performed with two varieties of bread wheat (Triticum aestivum L.), namely Almansor and Pirana and three varieties of durum wheat (Triticum durum Desf.) namely, Celta, Marialva and Hélvio. Excluding Pirana, which is a landrace, all other varieties are modern varieties obtained from Portuguese Wheat Breeding Program of National Institute for Agrarian and Veterinarian Research (INIAV - Elvas, Portugal).

\section{Allelic composition at glutenin loci}

Glutenin subunits (HMW-GS and LMW-GS) were extracted by sequential procedure of Singh et al. (1991) and separated on the basis of their mobility in SDS-PAGE using the discontinuous system of Laemmli, with $12 \%$ polyacrylamide gels.

The most determinant loci in bread wheat quality (Glu-A1, Glu-B1 and Glu-D1 coding for HMW-GS) and in durum wheat quality (Glu-A1, Glu-B1 coding for HMW-GS and Glu-B3 coding for LMW-GS) were analysed. The numbering and nomenclature of HMW-GS to bread and durum wheat followed Payne and Lawrence (1983) with minor modifications. LMW-GS from durum wheat were designed according to Nieto-Taladriz et al. (1997).

\section{Milling procedure}

Bread wheat samples were tempered to $16 \%$ moisture content with water, homogenized with a mixer Chopin MR2 (Group Tripette \& Renaud, France) and ground in a Chopin CD1 mill (Group Tripette \& Renaud, France) to obtain flour after 16 hours. Durum wheat samples were tempered in two steps according to Boggini (1991): first to $16.5 \%$ of moisture content and 3 hours latter to 17.5 of moisture content. These samples rested 24 hours, being then grounded in a Chopin CD2 mill (Group Tripette $\&$ Renaud, France) and purified in a laboratory purifier (Group Tripette \& Renaud, France) to obtain the semolina on which subsequent analyses were performed.

\section{Preliminary chemical characterization of flour/semolina samples}

$\mathrm{N}$ content of the flour/semolina samples was determined according to the Kjeldahl method (ISO 20483). Grain protein was determined by multiplying the total $\mathrm{N}$ by 5.7 as a conversion factor.

Wet and dry gluten contents were performed mechanically with Glutomatic System (Perten Instruments, Sweden) according to ISO 21415-2 and ISO 21415-4 to access to the quantity of gluten. Gluten strength was estimated in flour/semolina samples by Gluten index (ICC Standard No. 158) and SDS microsedimentation test (Dick and Quick, 1983). Ash content was determined in the flour/ semolina samples (900 $\pm 10^{\circ} \mathrm{C}, 2$ hours) according to Portuguese Standard NP 519.

The yellow pigment content, an essential quality factor of semolina, was determined according to ISO 11052 only in durum wheat samples. The extraction of the carotenoids was carried out with water saturated n-butanol and its quantification was performed in a spectrophotometer at $440 \mathrm{~nm}$ after filtration, using standard calibration curve of carotene.

\section{Preparation of flour/semolina blends}

Blends consisting of flour of bread wheat varieties (Almansor and Pirana) and semolina from durum wheat varieties (Celta, Hélvio and Marialva) were prepared careful to obtain homogenous samples. The replacement levels of $25 \%, 60 \%$ of flour with semolina were used. The replacement level $0 \%$ (bread wheat flour pure samples) and the replacement level $100 \%$ (durum wheat semolina pure samples) were used as controls.

For all tests, at least two determinations were carried out on each flour, semolina or flour/semolina blend.

\section{Dough evaluation of flour/semolina blends}

The physical properties of the dough from flour/semolina blends were characterized by farinograph method (ISO 
5530-1) and alveograph method (ISO 27971), the last procedure with lower modifications in the kneading time (12 min) and hydration (55\%) of semolina samples and flour/semolina blends, according to Peña (2000) and Ammar et al. (2000) respectively. A micro-alveograph Chopin MA87 equipped with a 50-g bowl (Group Tripette $\&$ Renaud, France) was used to estimate deformation energy (W) required to inflate the dough bubble until to rupture and curve configuration ratio $(\mathrm{P} / \mathrm{L}$ - relation between dough tenacity $(\mathrm{P})$ and extensibility $(\mathrm{L}))$. A microfarinograph equipped with a 10-g bowl (Brabender OHG Duisburg, Germany) was used to measure the consistency of the dough as it is formed, developed up to $500 \mathrm{UF}$ and changed with the time. The extrapolated data were: water absorption (Ab), development time (DT), stability (St) and degree of softening (DS).

\section{Bread evaluation of flour/semolina blends}

Breads were prepared using $400 \mathrm{~g}$ of flour/semolina blends, $6.4 \mathrm{~g}$ of salt, $4 \mathrm{~g}$ of dry yeast and variable water, equivalent to a consistency of $400 \mathrm{UF}$ in farinograph test which represent dough with good characteristics for breadmaking, according to a previous work (Brites et al, 2002). A basic baking program (thereabout 4 hours) was used in an automatic bread maker machine (Panasonic SD-206): rest $45 \mathrm{~min}$, knead $20 \mathrm{~min}$, rise $130 \mathrm{~min}$ and bake $50 \mathrm{~min}$.

For each bread, loaf volume by rapeseed displacement, loaf weight and crust and crumb colour were assessed individually. Crust and crumb colour were measured with Minolta CR 300 colorimeter (Minolta Corp., Ramsey, NJ) using the CIE $\mathrm{L}^{*} \mathrm{a}^{*} \mathrm{~b} *$ system. The colour parameters, lightness $\left(\mathrm{L}^{*}\right)$ and chromaticity (coordinates $\mathrm{a}^{*}$ and $\mathrm{b}^{*}$ ) were obtained: $a^{*}$ values reflect red to green colours and $b^{*}$ values reflect yellow to blue colours (with '+' values indicating 'yellowness').

\section{Statistical analysis}

Analysis of variance, ANOVA (SAS Institute, Cary, NC) was performed with the general linear model procedure. When significant differences were found in the ANOVA, means were compared using Tukey Student's test (significance level $\mathrm{P}<0.05$ ). Two sets of comparisons were made: first ANOVA was used to study the effects of different bread wheat varieties (Almansor and Pirana), durum wheat varieties (Celta, Hélvio and Marialva) and the replacement level of semolina (25 and 60\%) on technological parameters mean values of all the blends; Then this analysis was performed inside each group of bread wheat blends (blends containing Almansor and blends containing Pirana). The relationship between the quality traits was examined by Pearson correlation coefficients. Principal Component Analysis (PCA) was performed with NTSYS-pc version 2.0.

\section{RESULTS AND DISCUSSION}

\section{Allelic composition at glutenin loci}

The most determinant loci in bread wheat quality (Glu-A1, Glu-B1 and Glu-D1 coding for HMW-GS) and in durum wheat quality (Glu-B3 coding for LMW-GS) were characterized in the wheat samples of the present study. HMW-GS was also identified in durum wheat in order to validate its influence in breadmaking quality. Glutenin patterns of bread wheat (Almansor and Pirana) and of durum wheat (Celta, Hélvio and Marialva) are presented in Figs. 1 and 2, respectively. In Table 1, the composition of the most determinant loci in the quality of bread and durum wheat is presented. Some of these varieties have been previously studied by Igrejas et al. (1999) and Brites et al. (2000) and the composition here presented is in agreement with those studies.

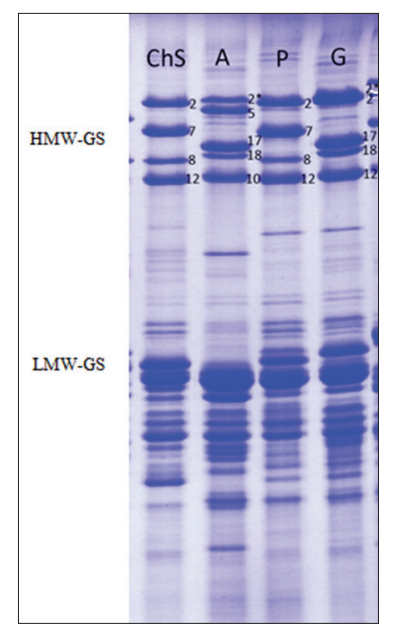

Fig 1. SDS-PAGE glutenin patterns of bread wheat varieties: ChS - Chinese Spring, A - Almansor, P - Pirana, G - Gabo. Chinese Spring and Gabo are references.

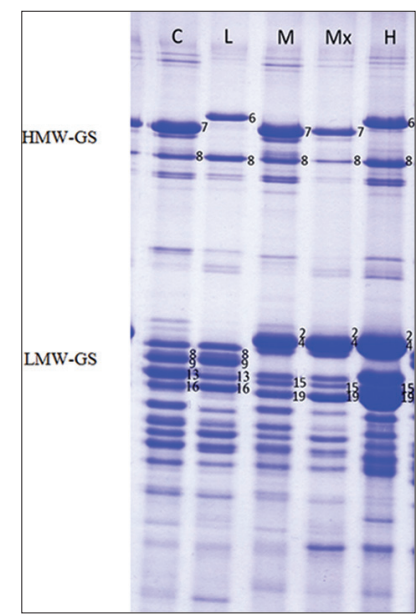

Fig 2. SDS-PAGE glutenin patterns of durum wheat varieties: C - Celta, $\mathrm{L}$ - Langdon, $\mathrm{M}$ - Marialva, Mx - Mexicali and $\mathrm{H}$ - Hélvio. Langdon and Mexicali are references. 
In what concerns bread wheat varieties, Almansor performs better than Pirana because it has HMW-GS of superior quality on Glu-D1 and Glu-A1 loci. The composition of the Glu-D1 locus is usually the one that most influences the strength of the dough, because the $5+10$ subunits have an additional cysteine residue, which enables to establish another intermolecular bond (Lafiandra et al., 1993). The presence of 2* subunit on Glu-A1 locus is also more favourable than the non-existence of any subunit as it happens in Pirana (Gupta et al., 1995).

In durum wheat varieties, the LMW-GS controlled by Glu-B3 locus plays a major role in determining gluten strength but HMW-GS also confer differential influence on durum wheat quality. Celta is inferior than Hélvio and Marialva because it has LMW-GS $8+9+13+16$ coded by $G l u-B 3$ locus, which are associated with poor quality in breadmaking quality (Nieto-Taladriz et al., 1997). Hélvio and Marialva differ on Glu-B1 locus, Hélvio has $6+8$ subunits and Marialva has $7+8$ subunits. The effect of this locus on breadmaking quality of durum wheat is not very well established. Some authors obtained higher gluten strength and loaf volume in lines possessing $6+8$ subunits (Peña, 2000; Ammar et al., 2000) and others found that $7+8$ subunits confer better breadmaking quality (Boggini and Pogna, 1989; Peña et al., 1994).

\section{Chemical characterization of flour/semolina samples}

Chemical composition of flour and semolina pure samples obtained with the five varieties was presented in Table 2 .

According to their allelic composition, flour samples (Almansor and Pirana) showed very different values for most quality parameters. Semolina samples (Celta, Hélvio and Marialva) presented intermediate values of protein and

Table 1: Glutenin composition in the most determinant loci in quality of bread wheat and durum wheat: HMW-GS were identified in all varieties and LMW-GS of Glu-B3 locus were identified in durum wheat

\begin{tabular}{lcccc}
\hline Variety & \multicolumn{3}{c}{ HMW-GS } & LMW-GS \\
\cline { 2 - 5 } & Glu-A1 & Glu-B1 & Glu-D1 & Glu-B3 \\
\hline Almansor & $2^{*}$ & $17+18$ & $5+10$ & - \\
Pirana & Null & $7+8$ & $2+12$ & - \\
Celta & Null & $7+8$ & - & $8+9+13+16$ \\
Hélvio & Null & $6+8$ & - & $2+4+15+19$ \\
Marialva & Null & $7+8$ & - & $2+4+15+19$ \\
\hline
\end{tabular}

gluten contents and higher values of ash content, when compared with the bread wheat flours.

SDS sedimentation test and Gluten Index are two indirect tests to esteem gluten strength, performed in a completely different way, but both reflected the worse allelic composition of variety Pirana in the bread wheat samples and Celta in the durum wheat samples.

The bright yellow colour of durum wheat is considered one of the main advantages of its use in baking products. It is known that the colour of durum products is influenced by some factors (carotenoid pigments, level of oxidative degradation by lipoxygenase LOX, processing conditions, etc.), but the carotenoid pigments are the most important (Trocccoli et al., 2000, He et al., 2009). This parameter was determined only on semolina samples and Celta variety showed the highest yellow pigment content.

Bread wheat variety, durum wheat variety and replacement level effects on physical properties of the dough and bread

Table 3 presents the rheological parameters and bread measurements of the flour and semolina pure samples obtained with the five varieties.

In the alveograph test, Almansor proved to be a good variety for baking because it forms dough with adequate

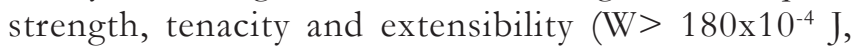
$0.5<\mathrm{P} / \mathrm{L}<1.2)$. Inversely, other varieties as Pirana formed weak dough inadequate to make bread. Dough formed with durum wheat were especially inelastic $(\mathrm{P} / \mathrm{L}>3)$, and this feature should be associated with the lower loaf volume obtained with durum wheat (Ammar et al., 2000, Sissons, 2008), similar in external appearance to that of weak bread flours (Boyacioglu and D'Appolonia, 1994a). The Farinograph test (Table 3) gave different results because it determines other kind of measurements and it is performed in different conditions (hydration adapted to achieve a constant consistency): Almansor showed good characteristics of dough development time (DT $>4 \mathrm{~min}$ ) and degree of softening (DS $<50 \mathrm{UF}$ ), but durum wheat varieties Hélvio and Marialva had better results concerning to the stability and degree of softening during the mixing process. Celta showed poor results in the two rheological tests.

Table 2: Chemical characterization of flour and semolina samples

\begin{tabular}{lccccccc}
\hline Variety & Protein (\%) & Wet gluten (\%) & Dry gluten $(\%)$ & Gluten index & SDS (mm) & Ash content (\%) & Yellow pigment (ppm) \\
\hline Almansor & $12.5 \pm 0.0$ & $36.9 \pm 1.9$ & $12.0 \pm 0.6$ & $80 \pm 5$ & $62 \pm 2$ & $0.50 \pm 0.02$ & - \\
Pirana & $9.3 \pm 0.1$ & $25.7 \pm 0.2$ & $8.0 \pm 0.1$ & $70 \pm 7$ & $54 \pm 0$ & $0.49 \pm 0.01$ & - \\
Celta & $11.9 \pm 0.2$ & $30.7 \pm 0.9$ & $9.7 \pm 0.0$ & $32 \pm 5$ & $26 \pm 1$ & $0.71 \pm 0.01$ & $7.3 \pm 0.0$ \\
Hélvio & $10.6 \pm 0.1$ & $28.1 \pm 2.0$ & $9.4 \pm 0.5$ & $91 \pm 1$ & $55 \pm 1$ & $0.61 \pm 0.04$ & $3.4 \pm 0.0$ \\
Marialva & $11.3 \pm 0.0$ & $28.8 \pm 0.3$ & $9.4 \pm 0.3$ & $87 \pm 0$ & $45 \pm 1$ & $0.62 \pm 0.06$ & $5.5 \pm 0.0$ \\
\hline
\end{tabular}


Table 3: Farinograph, alveograph and bread values of flour and semolina samples

\begin{tabular}{|c|c|c|c|c|c|}
\hline & \multicolumn{2}{|c|}{ Bread wheat } & \multicolumn{3}{|c|}{ Durum wheat } \\
\hline & Almansor & Pirana & Celta & Hélvio & Marialva \\
\hline \multicolumn{6}{|l|}{ Farinograph } \\
\hline $\mathrm{Ab}(\%)$ & $65.1 \pm 0.4$ & $58.2 \pm 0.6$ & $58.2 \pm 0.6$ & $57.8 \pm 0.1$ & $58.2 \pm 0.4$ \\
\hline DT (min) & $5.2 \pm 1.1$ & $2.7 \pm 0.7$ & $2.4 \pm 0.2$ & $6.0 \pm 1.1$ & $3.5 \pm 0.1$ \\
\hline St (min) & $6.5 \pm 1.1$ & $3.8 \pm 0.2$ & $1.9 \pm 0.0$ & $17.8 \pm 0.1$ & $9.5 \pm 1.6$ \\
\hline DS (UF) & $41 \pm 12$ & $61 \pm 1$ & $96 \pm 13$ & $10 \pm 1$ & $20 \pm 5$ \\
\hline \multicolumn{6}{|l|}{ Alveograph } \\
\hline$W\left(10^{-4} \mathrm{~J}\right)$ & $204 \pm 4$ & $93 \pm 17$ & $20 \pm 5$ & $108 \pm 8$ & $91 \pm 14$ \\
\hline $\mathrm{P} / \mathrm{L}$ & $1.1 \pm 0.1$ & $0.9 \pm 0.3$ & $3.9 \pm 0.4$ & $6.8 \pm 0.1$ & $3.0 \pm 0.4$ \\
\hline \multicolumn{6}{|l|}{ Bread } \\
\hline Loaf volume & $2785 \pm 28$ & $1713 \pm 28$ & $1390 \pm 20$ & $1852 \pm 7$ & $1960 \pm 14$ \\
\hline Loaf weight & $569 \pm 7$ & $558 \pm 10$ & $542 \pm 8$ & $555 \pm 15$ & $557 \pm 3$ \\
\hline $\mathrm{L}^{*}$ crumb & $67.4 \pm 3.2$ & $71.8 \pm 4.0$ & $72.2 \pm 3.9$ & $71.9 \pm 5.1$ & $77.4 \pm 3.0$ \\
\hline$b^{*}$ crumb & $10.8 \pm 0.8$ & $14.5 \pm 0.5$ & $23.1 \pm 3.2$ & $15.1 \pm 0.5$ & $19.6 \pm 1.1$ \\
\hline $\mathrm{L}^{*}$ crust & $68.5 \pm 3.7$ & $72.0 \pm 2.4$ & $64.4 \pm 3.1$ & $76.3 \pm 5.3$ & $78.2 \pm 3.4$ \\
\hline$b^{*}$ crust & $23.3 \pm 1.8$ & $19.6 \pm 2.0$ & $29.7 \pm 1.1$ & $23.1 \pm 1.2$ & $24.6 \pm 2.7$ \\
\hline
\end{tabular}

Four main factors can affect water absorption: flour and semolina particle size, damaged starch content, protein and pentosans content (Boyacioglu and D'Appolonia, 1994a, Sarpistein et al., 2007 and Sissons, 2008). Almansor flour sample presented the highest water absorption value, probably because a coarse semolina (particle size $<450$ $\mathrm{mm}$ ) with lower damaged starch content was used in durum wheat samples and Almansor wheat flour had a little higher protein content than other samples.

Flour and semolina pure samples were used as controls in baking test to compare with the blend results. Bread wheat Pirana and durum wheat Celta, Hélvio and Marialva formed low volume breads. Pirana is a Portuguese landrace commonly used in the past and as most of Portuguese landraces (previously studied in Brites et al., 1999), it is very weak. These two studies evidenced that in the past Portuguese traditional bread probably was made using mixtures that contained other cereals.

Table 4 presented ANOVA results for farinograph, alveograph and bread parameters of flour/semolina blends considering three sources of variation: bread wheat variety, durum wheat variety and replacement level of durum wheat in the bread.

The three sources were important to explain the variation of quality traits quality traits and the bread wheat variance components were usually larger than components from durum wheat and replacement level (excluding farinograph stability, alveograph P/L, loaf weight and almost all bread colour related parameters), because the two bread wheat varieties used in the blends were very different. To clarify the true effect of durum wheat addition on the dough rheological behaviour and on bread, ANOVA (data not
Table 4: Analysis of variance for farinograph, alveograph and bread parameters of flour/semolina blends obtained with 2 replacement levels of durum wheat $(25 \%$ and $60 \%)$, two bread wheat Almansor and Pirana, and three durum wheat, Celta, Hélvio and Marialva

\begin{tabular}{|c|c|c|c|c|}
\hline & \multicolumn{4}{|c|}{ Source of variation (F values) } \\
\hline & $\begin{array}{l}\text { Bread } \\
\text { wheat }\end{array}$ & $\begin{array}{l}\text { Durum } \\
\text { wheat }\end{array}$ & $\begin{array}{c}\text { Replacem. } \\
\text { level }\end{array}$ & Model \\
\hline & $(d f=1)$ & $(d f=2)$ & $(d f=1)$ & $(d f=4)$ \\
\hline \multicolumn{5}{|l|}{ Farinograph } \\
\hline $\mathrm{Ab}(\%)$ & $175.52^{\star \star \star}$ & $1.73^{\text {ns }}$ & $6.64^{*}$ & $46.41^{* * *}$ \\
\hline DT (min) & $18.17^{\star * *}$ & $8.18^{\star *}$ & $0.02^{\text {ns }}$ & $8.64^{* * *}$ \\
\hline St (min) & $14.76^{\star *}$ & $22.27^{\star * *}$ & $4.69^{*}$ & $16.00^{* \star *}$ \\
\hline DS (UF) & $10.85^{\star *}$ & $8.50^{\star \star}$ & $0.13^{\text {ns }}$ & $6.99^{\star *}$ \\
\hline \multicolumn{5}{|l|}{ Alveograph } \\
\hline W (10-4J) & $64.76^{\star * *}$ & $30.09^{* * *}$ & $7.40^{*}$ & $33.08^{* * *}$ \\
\hline $\mathrm{P} / \mathrm{L}$ & $0.47^{\text {ns }}$ & $1.55^{\mathrm{ns}}$ & $20.19^{\star * *}$ & $5.94^{\star \star}$ \\
\hline \multicolumn{5}{|l|}{ Bread } \\
\hline Loaf volume (ml) & $84.54^{\star \star \star}$ & $21.22^{\star \star \star}$ & $18.23^{\star * \star}$ & $36.30^{* * *}$ \\
\hline Loaf weight $(\mathrm{g})$ & $1.73^{\text {ns }}$ & $0.07^{\mathrm{ns}}$ & $2.27^{\mathrm{ns}}$ & $1.04^{\mathrm{ns}}$ \\
\hline$L^{*}$ crumb & $1.25^{\mathrm{ns}}$ & $0.46^{\mathrm{ns}}$ & $5.63^{*}$ & $1.95^{\mathrm{ns}}$ \\
\hline$b^{*}$ crumb & $0.72^{\text {ns }}$ & $5.67^{\star}$ & $23.17^{\star \star *}$ & $8.81^{* \star *}$ \\
\hline$L^{*}$ crust & $4.61^{*}$ & $6.09^{* \star}$ & $0.37^{\text {ns }}$ & $4.29^{*}$ \\
\hline$b^{*}$ crust & $4.75^{*}$ & $1.48^{\mathrm{ns}}$ & $0.53^{\mathrm{ns}}$ & $2.06^{\mathrm{ns}}$ \\
\hline
\end{tabular}

shown) and comparison between means were performed inside the group of blends containing bread wheat Almansor and inside the group of blends containing bread wheat Pirana (Tables 5 and 6).

The mean results of farinograph test showed that the inclusion of durum wheat Hélvio in the blends with the two bread wheat was the most advantageous for the dough stability, but the mean results of alveograph test and bread parameters showed that there were not significant differences in dough strength and loaf volume of blends containing Hélvio and Marialva (Table 5). These results are in agreement with their similar composition on $G l u-B 3$ locus, the most important locus to durum wheat quality. As it was expected, blends with Celta had worst alveograph results because they exhibited more weak and viscous dough and lower loaf volume, according to its inferior allelic composition on Glu-B3 locus.

The comparison between the results of the blend samples and pure bread wheat samples (Tables 3 and 5) showed that adding the three durum wheat to Almansor had a deleterious effect on the main quality parameters. Inversely the addition of Hélvio and Marialva durum wheat to Pirana can improve the bread volume. Some authors as Boggini and Pogna (1990) and Torbica et al. (2011) suggested durum wheat as improvement agent in breadmaking, to correct some wheat flours characterized by poor quality or damaged protein structure. 
Table 5: Comparison between group means of quality traits for flour/semolina blends obtained with Almansor or Pirana as bread wheat and three durum wheat (Celta, Hélvio, Marialva)

$$
\text { Almansor Pirana }
$$

Celta Hélvio Marialva Celta Hélvio Marialva

\begin{tabular}{lcccccc}
\hline Farinograph & & & & & & \\
Ab (\%) & $62.3 \mathrm{a}$ & $61.9 \mathrm{a}$ & $62.2 \mathrm{a}$ & $57.5 \mathrm{a}$ & $56.5 \mathrm{~b}$ & $55.7 \mathrm{~b}$ \\
DT (min) & $3.7 \mathrm{~b}$ & $7.0 \mathrm{a}$ & $4.7 \mathrm{~b}$ & $2.6 \mathrm{a}$ & $3.9 \mathrm{a}$ & $2.8 \mathrm{a}$ \\
St (min) & $3.6 \mathrm{~b}$ & $9.6 \mathrm{a}$ & $6.1 \mathrm{~b}$ & $2.2 \mathrm{c}$ & $5.8 \mathrm{a}$ & $4.4 \mathrm{~b}$ \\
DS (UF) & $61 \mathrm{a}$ & $23 \mathrm{~b}$ & $45 \mathrm{ab}$ & $70 \mathrm{a}$ & $51 \mathrm{~b}$ & $65 \mathrm{ab}$ \\
Alveograph & & & & & & \\
W (10-4J) & $75 \mathrm{~b}$ & $137 \mathrm{a}$ & $133 \mathrm{a}$ & $45 \mathrm{~b}$ & $82 \mathrm{a}$ & $78 \mathrm{a}$ \\
P/L & $1.03 \mathrm{ab}$ & $1.28 \mathrm{a}$ & $0.84 \mathrm{~b}$ & $1.16 \mathrm{a}$ & $0.87 \mathrm{a}$ & $0.87 \mathrm{a}$ \\
Bread & & & & & & \\
Loaf volume (ml) & $2140 \mathrm{~b}$ & $2370 \mathrm{a}$ & $2490 \mathrm{a}$ & $1648 \mathrm{~b}$ & $2043 \mathrm{a}$ & $1990 \mathrm{a}$ \\
Loaf weight (g) & $568 \mathrm{a}$ & $564 \mathrm{a}$ & $558 \mathrm{a}$ & $554 \mathrm{~b}$ & $555 \mathrm{~b}$ & $565 \mathrm{a}$ \\
L* crumb & $69.9 \mathrm{a}$ & $72.1 \mathrm{a}$ & $71.0 \mathrm{a}$ & $72.1 \mathrm{a}$ & $72.7 \mathrm{a}$ & $72.3 \mathrm{a}$ \\
b* crumb & $16.2 \mathrm{a}$ & $12.4 \mathrm{~b}$ & $14.8 \mathrm{a}$ & $16.1 \mathrm{a}$ & $13.6 \mathrm{a}$ & $15.5 \mathrm{a}$ \\
L* crust & $69.9 \mathrm{a}$ & $73.2 \mathrm{a}$ & $71.6 \mathrm{a}$ & $68.4 \mathrm{~b}$ & $80.4 \mathrm{a}$ & $77.9 \mathrm{a}$ \\
b* crust & $23.6 \mathrm{a}$ & $23.8 \mathrm{a}$ & $26.8 \mathrm{a}$ & $25.4 \mathrm{a}$ & $20.0 \mathrm{~b}$ & $20.6 \mathrm{~b}$
\end{tabular}

Each value represents the mean value $(n=4)$. Within each parameter, different letters in the same line refer to significant differences between blends with different durum wheat

Table 6: Comparison between group means of quality traits for flour/semolina blends obtained with Almansor or Pirana as bread wheat and 2 replacement levels of durum wheat $(25 \%$ and $60 \%)$

\begin{tabular}{|c|c|c|c|c|}
\hline & \multicolumn{2}{|c|}{ Almansor } & \multicolumn{2}{|c|}{ Pirana } \\
\hline & 0.25 & 0.60 & 0.25 & 0.60 \\
\hline \multicolumn{5}{|l|}{ Farinograph } \\
\hline $\mathrm{Ab}(\%)$ & $63.3 a$ & $60.9 \mathrm{~b}$ & $56.4 \mathrm{a}$ & $56.7 a$ \\
\hline DT (min) & $5.6 a$ & $4.7 a$ & $2.7 a$ & $3.5 a$ \\
\hline St (min) & $5.4 a$ & $7.4 a$ & $3.8 \mathrm{a}$ & $4.4 \mathrm{a}$ \\
\hline DS (UF) & $41.7 a$ & $43.8 \mathrm{a}$ & $64.6 \mathrm{a}$ & $58.3 a$ \\
\hline \multicolumn{5}{|l|}{ Alveograph } \\
\hline W (10-4J) & $126.0 a$ & $103.8 \mathrm{~b}$ & $72.9 a$ & $63.5 a$ \\
\hline $\mathrm{P} / \mathrm{L}$ & $0.87 b$ & $1.23 a$ & $0.59 b$ & $1.34 a$ \\
\hline \multicolumn{5}{|l|}{ Bread } \\
\hline $\begin{array}{l}\text { Loaf } \\
\text { volume (ml) }\end{array}$ & $2508 a$ & $2159 b$ & $1923 a$ & $1863 a$ \\
\hline Loaf weight (g) & $567 a$ & $559 a$ & $560 a$ & $556 a$ \\
\hline$L^{*}$ crumb & $70.5 a$ & $71.5 a$ & $75.6 a$ & $69.0 \mathrm{~b}$ \\
\hline$b^{*}$ crumb & $13.5 b$ & $15.4 \mathrm{a}$ & $12.2 b$ & $18.0 \mathrm{a}$ \\
\hline $\mathrm{L}^{*}$ crust & $71.0 \mathrm{a}$ & $72.2 \mathrm{a}$ & $77.3 a$ & $73.9 a$ \\
\hline$b^{*}$ crust & $23.8 \mathrm{a}$ & $25.7 a$ & $22.0 a$ & $22.0 a$ \\
\hline
\end{tabular}

Each value represents the mean value $(n=6)$. Within each parameter, different letters in the same line refer to significant differences between blends with different replacement level of durum wheat

Concerning to colour parameters (Table 5), the type of durum wheat only significantly influenced the yellowish colour ( $\mathrm{b}^{*}$ ) of the bread crumb containing Almansor and of the bread crust containing Pirana: Celta and Marialva were more advantageous in the first situation and Celta in the second situation. In opposition, blends with Pirana and Celta had lower bread crust lightness $\left(\mathrm{L}^{*}\right)$.

The $\mathrm{P} / \mathrm{L}$ ratio, bread volume and crumb colour component $b^{*}$ were the parameters more significantly affected by the level of replacement of durum wheat (Table 4). The increase of the level of durum wheat in both types of blends increased $\mathrm{P} / \mathrm{L}$ and $\mathrm{b}^{*}$ and also decreased alveograph deformation energy and loaf volume on blends with Almansor (Table 6).

\section{Relation between quality traits}

Bread volume was significantly correlated with almost all rheological parameters but deformation energy was the most significantly correlated $(\mathrm{p}<0.001$, Table 7$)$. These results were in agreement with Marchylo et al. (2001), that obtained significant correlations between bread volume and alveograph deformation energy and farinograph development time in a study with 54 durum wheat. Bread weight was significantly correlated with volume $(\mathrm{p}<0.001)$ and alveograph parameters $(\mathrm{p}<0.01$ with $\mathrm{W}$ and $\mathrm{p}<0.05$ with $\mathrm{P} / \mathrm{L}$ ), but it was not correlated with farinograph parameters, except water absorption $(\mathrm{p}<0.05)$.

Concerning to colour parameters, $\mathrm{b}^{*} \mathrm{crumb}$ was the most significantly related with alveograph $(\mathrm{p}<0.001$ with $\mathrm{W}$, $\mathrm{p}<0.05$ with $\mathrm{P} / \mathrm{L})$ and bread parameters $(\mathrm{p}<0.001$ with volume, $\mathrm{p}<0.05$ with weight) probably because these parameters had been affected by the replacement level of durum wheat. The parameter $b^{*}$ crust was significantly correlated with bread weight $(\mathrm{p}<0.001)$ and the other colour parameters: $b^{*}$ crumb ( $\left.p<0.05\right), L^{*}$ crust $(p<0.001)$.

The farinograph parameters were significantly related to each other and with the alveograph deformation energy as expected (Marchylo et al., 2001). P/L ratio only was significantly correlated with farinograph stability $(\mathrm{p}<0.001)$.

\section{Principal component analysis (PCA)}

The components 1, 2 and 3 explained $79.7 \%$ of total variance in the data set (Table 8). An overview of the results from the different tests was given in PCA plots with component 1 and 2 (Fig. 3). The first principal component accounted for $39.4 \%$ of the validation variance and reflected the quality of flour/semolina blends. It was strongly correlated with five of the original variables, suggesting that these five criteria varied together and they were the most important parameters to distinguish the best blends: the relation was positive with W, Volume, DT and negative with DS and $\mathrm{b}^{*}$ crumb. Samples with higher dough strength and volume appeared in the right side (as Almansor 100\% and almost all blends containing Almansor), whereas samples with lower strength and volume appeared in the left side (as Celta 100\% and blend containing Pirana and Celta 60\%). The second principal component accounted for $20.9 \%$ of the validation variance and was strongly correlated with three of the original variables: $L^{*}$ crust, 


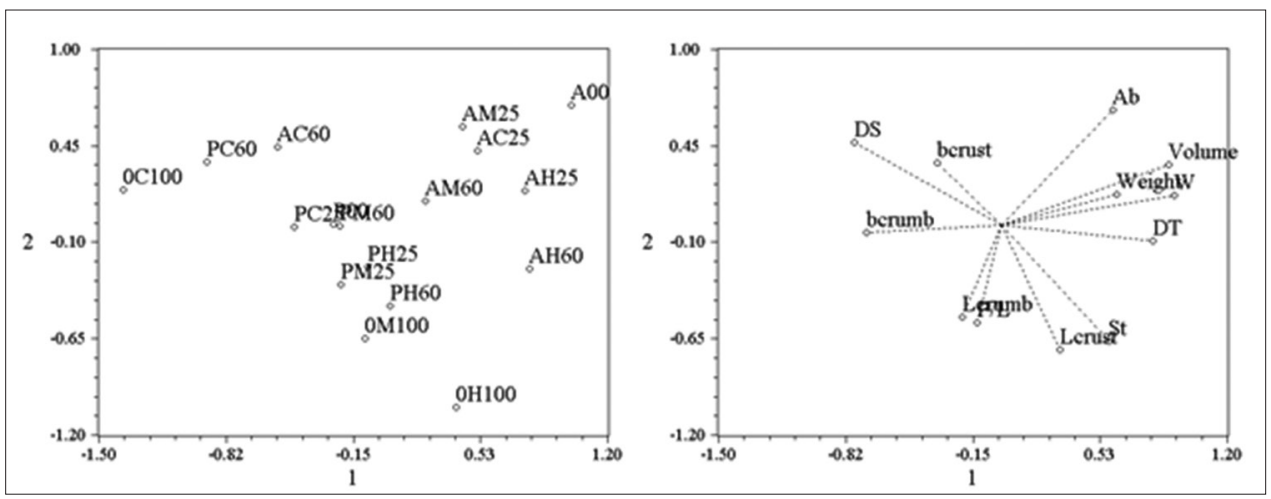

Fig 3. Relationship between the two principal components for the rheological and bread variables of the blends studied: Score plot of blends (left) and loading plot of variables (right). The blends were designed by 3 digits: $1^{\text {st }}$ - bread wheat composition $(0-$ without, A - Almansor, $\mathrm{P}$ - Pirana), $2^{\text {nd }}$ - durum wheat composition ( 0 - without, C - Celta, $\mathrm{H}$ - Hélvio, $\mathrm{M}$ - Marialva), $3^{\text {rd }}-$ replacement level of durum wheat $(0,25$, $60,100 \%)$.

Table 7: Pearson correlation coefficients among quality parameters obtained with the results of all flour/semolina blends and controls $(n=34)$

\begin{tabular}{|c|c|c|c|c|c|c|c|c|c|c|c|}
\hline & $A b$ & DT & St & DS & W & P/L & Vol & Weight & $L^{*}$ crumb & b*crumb & L*crust \\
\hline$\overline{\mathrm{DT}}$ & $0.50^{* *}$ & & & & & & & & & & \\
\hline St & $0.04^{\mathrm{ns}}$ & $0.63^{* * *}$ & & & & & & & & & \\
\hline DS & $-0.24^{\mathrm{ns}}$ & $-0.70^{\star \star *}$ & $-0.84^{\star \star *}$ & & & & & & & & \\
\hline W & $0.65^{\star \star \star}$ & $0.66^{* * *}$ & $0.46^{\star *}$ & $-0.59^{\star * *}$ & & & & & & & \\
\hline $\mathrm{P} / \mathrm{L}$ & $-0.18^{\mathrm{ns}}$ & $0.15^{\mathrm{ns}}$ & $0.62^{\star \star \star}$ & $-0.30^{\text {ns }}$ & $-0.16^{\text {ns }}$ & & & & & & \\
\hline Vol & $0.73^{* * *}$ & $0.60^{* * *}$ & $0.24^{\text {ns }}$ & $-0.48^{* *}$ & $0.89^{* * *}$ & $-0.38^{*}$ & & & & & \\
\hline Weight & $0.38^{*}$ & $0.16^{\mathrm{ns}}$ & $0.04^{\text {ns }}$ & $-0.28^{\text {ns }}$ & $0.46^{\star *}$ & $-0.34^{*}$ & $0.60^{\star \star *}$ & & & & \\
\hline $\mathrm{L}^{*}$ crumb & $-0.37^{*}$ & $-0.17^{\mathrm{ns}}$ & $0.08^{\text {ns }}$ & $-0.08^{\text {ns }}$ & $-0.22^{\mathrm{ns}}$ & $0.05^{\text {ns }}$ & $-0.26^{\mathrm{ns}}$ & $-0.24^{\text {ns }}$ & & & \\
\hline$b^{*}$ crumb & $-0.27^{\text {ns }}$ & $-0.34^{\text {ns }}$ & $-0.20^{\text {ns }}$ & $0.30^{\text {ns }}$ & $-0.63^{\star * *}$ & $0.40^{*}$ & $-0.59^{\star \star \star}$ & $-0.41^{*}$ & $-0.08^{\text {ns }}$ & & \\
\hline $\mathrm{L}^{*}$ crust & $-0.46^{* *}$ & $0.04^{\text {ns }}$ & $0.38^{*}$ & $-0.35^{\star}$ & $0.12^{\text {ns }}$ & $-0.04^{\text {ns }}$ & $0.13^{\text {ns }}$ & $0.32^{\text {ns }}$ & $0.38^{*}$ & $-0.29^{\text {ns }}$ & \\
\hline$b^{*}$ crust & $0.30^{\text {ns }}$ & $0.00^{\text {ns }}$ & $-0.12^{\text {ns }}$ & $0.20^{\text {ns }}$ & $-0.15^{\text {ns }}$ & $0.23^{\text {ns }}$ & $-0.14^{\text {ns }}$ & $-0.54^{\star * *}$ & $0.08^{\text {ns }}$ & $0.36^{*}$ & $-0.70^{* * \star}$ \\
\hline
\end{tabular}

${ }_{*, * *, * * *}$ stands for significant at the $0.05,0.01$ and 0.001 levels of probability, respectively

Table 8: Correlations and proportion of the variance between the initial variables and the principal components

\begin{tabular}{lccc}
\hline Initial variables & \multicolumn{3}{c}{ Components } \\
\cline { 2 - 4 } & $\mathbf{1}$ & $\mathbf{2}$ & $\mathbf{3}$ \\
\hline Weight & 0.612 & 0.172 & 0.500 \\
Volume & 0.891 & 0.342 & 0.058 \\
Ab & 0.593 & 0.658 & -0.340 \\
DT & 0.804 & -0.095 & -0.431 \\
St & 0.573 & -0.663 & -0.450 \\
DS & -0.780 & 0.472 & 0.279 \\
L $^{*}$ crumb & -0.208 & -0.528 & 0.156 \\
b* crumb $^{*}$ crust & -0.717 & -0.045 & -0.374 \\
b* crust & 0.311 & -0.714 & 0.554 \\
P/L & -0.342 & 0.353 & -0.736 \\
W & -0.127 & -0.558 & -0.687 \\
Total & 0.919 & 0.167 & -0.089 \\
Proportion of variance \% & 4.733 & 2.505 & 2.217 \\
Total Proportion of variance \% & 39.4 & 20.9 & 19.4 \\
\hline
\end{tabular}

farinograph stability and water absorption. The relation with $L^{*}$ crust and stability was negative and it was positive with water absorption. This situation was evidenced by the positioning of samples Almansor 100\% (L*crust $=68.5$,
St $=6.5 \mathrm{~min}, \mathrm{Ab}=65.1 \%)$ and Hélvio $100 \%\left(\mathrm{~L}^{*}\right.$ crust $=$ $76.3, \mathrm{St}=17.8 \mathrm{~min}, \mathrm{Ab}=57.8 \%$ ).

The third principal component accounted for $19.4 \%$ of the validation variance, and the $\mathrm{b}^{*}$ crust and $\mathrm{P} / \mathrm{L}$ were the most important parameters to differentiate samples.

\section{CONCLUSIONS}

Breeding programs traditionally have selecting durum wheat for pasta quality because of its commercial importance. This study showed that it is possible to obtain bread with acceptable characteristics if blends of bread and durum wheat are used. For this purpose, it is essential to select bread wheat and durum wheat with high quality to promote the formation of a strong gluten matrix: a good allelic composition on Glu-D1 locus (5+10 subunits) in bread wheat and on Glu-B3 locus $(2+4+15+19$ subunits) in durum wheat. The use of blends containing durum and bread wheat usually produces lower bread volume but give very interesting characteristics such as yellowish crumb colour, finer and uniform crumb structure and good taste. 


\section{REFERENCES}

Ammar, K., E. K. Warren and C. F. Morris. 2000. Bread making quality of selected durum wheat genotypes and its relationship with high molecular weight gluten in subunits allelic variation and gluten protein polymeric composition. Cereal Chem. 77(2): 230-236.

Boggini, G. 1991. Valutazione della qualitá pastificatoria del grano duro mediante l'alveografo di Chopin. Molini D'Italia. p151-153.

Boggini, G. and N. E. Pogna. 1989. The breadmaking quality and storage protein composition of Italian durum wheat. J. Cereal Sci. 9: 131-138.

Boggini, G. and N. E. Pogna. 1990. Use of durum wheat to improve the bread making quality of soft wheat. Tec. Molitoria. 41: 1025-1030.

Boyacioglu, M. H. and B. L. D'Appolonia. 1994a. Characterization and utilization of durum wheat for breadmaking. I. Comparison of chemical, rheological, and baking properties between bread wheat flour and durum wheat flours. Cereal Chem. 71: 21-28.

Boyacioglu, M. H. and B. L. D'Appolonia. 1994b. Characterization and utilization of durum wheat for breadmaking. III. Staling properties of bread baked from bread wheat flours and durum wheat flours. Cereal Chem. 71: 34-41.

Boyacioglu, M. H. and B. L. D'Appolonia. 1994c. Durum wheat and bread products. Cereal Foods World. 39: 168-174.

Brites, C. and J. M. Carrillo 2000. Influence of high molecular weight (HMW) and low molecular weight (LMW) glutenin $S$ subunits controlled by Glu-1 and Glu-3 Loci on durum wheat quality. Cereal Chem. 78(1): 59-63.

Brites, C. and A. S. Bagulho. 1999. Avaliação da qualidade tecnológica de uma colecção de variedades de trigo mole Portugueses. Melhoramento. 36: 15-26.

Brites, C., A. S. Bagulho, M. C. Muacho, C. Gomes, P. E. Antunes and B. Maçãs. 2002. Análise da produtividade e aptidão tecnológica de variedades comerciais de trigo mole. Melhoramento. 38: 107-120.

Dhaka, V. and B. S. Khatkar. 2015. Effects of gliadin/glutenin and HMW-GS/LMW-GS ratio on dough rheological properties and bread-making potential of wheat varieties. J. Food Qual. 38: 71-82.

Dick, J. W. and J. S. Quick. 1983. A modified screening test for rapid estimation of gluten strength in early - Generation durum wheat breeding lines. Cereal Chem. 60: 315-318.

Gupta, R. B., Y. Popineau, J. Lefebvre, M. Cornec, G. J. Lawrence and F. MacRitchie. 1995. Biochemical basis of flour properties in bread wheats. II. Changes in polymeric protein formation and dough/gluten properties associated with the loss of low $\mathrm{Mr}$ or high Mr Glutenin subunits. J. Cereal Sci. 21: 103-116.

Hareland, G.A. and D.P. Puhr. 1998. Baking performance of durum and soft wheat flour in a Ssponge-dough breadmaking procedure. Cereal Chem. 75(6): 830-835.

He, X., J. Wang, K. Ammar, R. J. Peña, X. Xia and Z. He. 2009. Allelic variants at the $P s y-A 1$ and $P s y-B 1$ loci in durum wheat and their associations with grain yellowness. Crop Sci. 49: 2058-2064.

ICC Standard No 158. 1995. Gluten Index Method for Assessing Gluten Strength in Durum Wheat. International Association for Cereal Science and Technology, p. 6.

Igrejas G., H. Guedes-Pinto, V. Carnide and G. Branlard. 1999. The high and low molecular weight Glutenin subunits and $\omega$-gliadin composition of bread and durum wheats commonly grown in Portugal. Plant Breed. 118: 297-302.

ISO, 11052. 2006. Durum Wheat Flour and Semolina - Determination of Yellow Pigment Content. International Standardization
Organization, p. 5.

ISO, 20483. 2006. Cereals and Pulses - Determination of the Nitrogen Content and Calculation of the Crude Protein Content - Kjeldahl Method, International Standardization Organization, p. 13.

ISO, 21415-2 (E). 2006. Wheat and Wheat Flour- Gluten Content - Part 2: Determination of Wet Gluten by Mechanical Means. International Standardization Organization, p. 11.

ISO, 21415-4 (E). 2006. Wheat and Wheat Flour - Gluten Content Part 4: Determination of Dry Gluten from Wet Gluten by a Rapid Drying Method. International Standardization Organization, p. 6.

ISO, 27971 (E). 2008. Cereals and cereal products - Common wheat (Triticum aestivum L.) - Determination of alveograph properties of dough at constant hydration from commercial or test flours and test milling methodology. International Standardization Organization, p. 52.

ISO, 3093 (E). 2009. Wheat. rye and their flours. Durum Wheat and Durum Wheat Semolina - Determination of the Falling Number According to Hagberg-Perten. International Standardization Organization, p. 13.

ISO 5530-1. 2013. Wheat Flour - Physical Characteristics of Doughs - Part 1: Determination of Water Absorption and Rheological Properties Using a Farinograph. International Standardization Organization, p. 26.

Lafiandra D., R. D'Ovidio, E. Porceddu, B. Margiotta and G. Colaprico. 1993. New data supporting high Mr glutenin subunit 5 as the determinant of quality differences among the pairs $5+10$ vs. $2+$ 12. J. Cereal Sci. 18: 197-205.

Licciardello F., V. Rizzo, O. Grillo, G. Venora, G. Muratore. 2013. Bread-making performances of durum wheat semolina, as affected by ageing. J. Cereal Sci. 57: 372-376.

Liu, C. Y., K. W. Shepherd and A. J. Rathjen. 1996. Improvement of durum wheat pastamaking and breadmaking qualities. Cereal Chem. 73(2): 155-166.

Marchylo, B. A., J. E. Dexter, F. R. Clarke, J. M. Clarke and K. R. Preston. 2001. Relationships among bread-making quality, gluten strength, physical dough properties and pasta cooking quality for some Canadian durum wheat genotypes. Can. J. Plant Sci. 81: 611-620.

Nieto-Taladriz, M. T., M. Ruiz, M. C. Martínez, J. F. Vázquez and J. M. Carrillo. 1997. Variation and classification of B lowmolecular-weight glutenin subunit alleles in durum wheat. Ther. Appl. Genet. 95: 1155-1160.

NP, 519. 1993. Cereais e derivados. Determinação do teor de cinza a $900^{\circ} \mathrm{C}$. Processo corrente. Instituto Português da Qualidade, p. 5.

Payne, P. I. and G. J. Lawrence. 1983. Catalogue of alleles for the complex gene loci Glu-A1, Glu-B1 and Glu-D1 which code for high-molecular-weight subunits of glutenin in hexaploid wheat. Cereal Res. Commun. 11: 29-35.

Payne, P. I., M. A. Nightingale, A. F. Krattiger and L. M. Holt. 1987. The relationship between HMW glutenin subunit composition and the bread-making quality of British-grown wheat-varieties. J. Sci. Food Agric. 40: 51-65.

Peña, R. J. 2000. Durum wheat for pasta and bread making. Comparison of methods used in breeding to determine gluten quality-related parameters. In: Royo, C., M. M. Nachit, N D. Fonzo and J. L. Arauz, (Eds.), Durum Wheat Improvement in the Mediterranean Region: New Challenges. CIHEAM, Zaragoza, Options Méditerranéennes Série A. Séminaires Méditerranéens. Vol. 40. Pp. 423-430.

Peña, R. J., J. Zarco-Hernandez, A. Amaya-Celis and A. Mujeeb-Kazi. 
1994. Relationships between chromosome 1B-encoded glutenin subunit compositions and bread-making quality characteristics of some durum wheat (Triticum turgidum) cultivars. J. Cereal Sci. 19: 243-249.

Sapirstein, H. D., P. David, K. R. Preston and J. E. Dexter. 2007. Durum wheat breadmaking quality: Effects of gluten strength, protein composition, semolina particle size and fermentation time. J. Cereal Sci. 45: 150-161.
Singh, N. K., K. W. Shepherd and G. B. Cornish. 1991. A simplified SDS-PAGE procedure for separating LMW subunits of glutenin. J. Cereal Sci. 14: 203-208.

Sissons, M. 2008. Role of durum wheat composition on the quality of pasta and bread. Food. 2(2): 75-90.

Torbica, A., M. Hadnadev, T. D. Hadnadev. 2011. Possibility of using durum wheat flour as an improvement agent in bread making process. Proc. Food Sci. 1: 1628-1632. 